\title{
AMARElo (2019), DE EMICIDA: POR UMA PEDAGOGIA DO ENCONTRO
}

AMARELO (2019), BY EMICIDA: FOR A PEDAGOGY OF THE ENCOUNTER

DOI: $10.23926 /$ RPD.2526-2149.2020.v5.n2.p857-869.id802

\section{Carlos Henrique de \\ Barros Roncolato}

Graduando em Pedagogia

pelo Centro Técnico-

Educacional Superior do

Oeste Paranaense (CTESOP)

carlosroncolato92@gmail.co

$\underline{\mathrm{m}}$

\section{Karla Daniel Martins de Souza Albuquerque Mestranda em Letras pela Universidade Estadual do Oeste do Paraná \\ (UNIOESTE) \\ profkarladaniel@gmail.com}

\section{Adenilson de Barros} de Albuquerque

Doutor em Letras pela Universidade Estadual do Oeste do Paraná (UNIOESTE)

Professor no Instituto

Federal do Paraná/campus Umuarama (IFPR)

adenilsonbar@gmail.com
Resumo: Este artigo apresenta uma leitura do álbum AmarElo (2019), de Emicida. O objetivo é relacionar a construção das faixas com uma proposta de postura educacional na sociedade contemporânea. Visamos, especialmente, o contexto do Ensino Médio, pois os temas e as abordagens dialogam com possibilidades de análise e atuação docente em vários aspectos. A partir de uma perspectiva fenomenológica e de pressupostos de Paulo Freire, trazemos alternativas de reflexão no espaço escolar.

Palavras-chave: Educação. Escola. Sociedade.

\begin{abstract}
This article presents a reading of the AmarElo (2019) album, by Emicida. The goal is to relate the songs's construction with a propose of educational posture in the contemporaneous society. We aim, specially, the context of High School, because the subjects and the approaches dialogue with analisys and actuation's posibilities in many aspects. From a phenomenological perspective and Paulo Freire's assumptions, we bring alternatives for reflection in the school space.
\end{abstract}

Keywords: Education. School. Society. 


\section{INTRODUÇÃO}

Este estudo surge a partir do interesse comum dos autores na obra de Leandro Roque de Oliveira, o Emicida, e dos estudos de Pedagogia, Linguística e Literatura que, respectivamente, desempenhamos, vinculados direta ou indiretamente à atuação em sala de aula. Sem direcionarmos nossa abordagem especificamente a uma disciplina, pretendemos discutir a constituição do álbum AmarElo (2019) que, em grande medida, apresenta-se como resultado artístico simbólico e inspirador da prática docente na sociedade contemporânea. Ao partirmos do pressuposto de que "[...] a educação é uma forma de intervenção no mundo. Intervenção que, além do conhecimento dos conteúdos bem ou mal ensinados e/ou aprendidos, implica tanto o esforço de reprodução da ideologia dominante quanto o seu desmascaramento" (FREIRE, 2011, p. 75), compreendemos que os encontros na obra aqui em destaque revelam-se como guia e caminho possíveis de reflexão.

Atentamos para as parcerias, temas, linguagem, referências e o diálogo entre distintas formas de expressão, misturadas em uma espécie de mosaico de citações em que o artista busca reelaborar leituras, expressões e perspectivas a partir do cotidiano e das memórias que o emolduram como sujeito. A liberdade para o conhecimento é, ao mesmo tempo, fruto de ação e inquietude frente aos moldes e modelos direcionados histórica e socialmente como prontos e acabados. AmarElo, portanto, pode ser encarado como um espelho para a atuação docente e é nessa direção que propomos pensar, de maneira especial, porém, não unicamente, o Ensino Médio - nosso olhar acadêmico, assim como a arte, não pretende fechar-se na exclusividade de um contexto - em que professores e alunos deparam-se com problemáticas importantes não somente no interior das escolas.

Recorremos uma vez mais a Paulo Freire (2015, p. 98) que nos idos da década de 1960 afirmou: “A educação é um ato de amor e, por isso, um ato de coragem. Não pode temer o debate. A análise da realidade. Não pode fugir à discussão criadora, sob pena de ser uma farsa." Mais adiante, o educador brasileiro questiona um modelo pedagógico impositivo no qual:

\footnotetext{
Ditamos ideias. Não trocamos ideias. Discursamos aulas. Não debatemos ou discutimos temas. Trabalhamos sobre o educando. Não trabalhamos com ele. Impomos-lhe uma ordem a que ele não adere, mas se acomoda. Não lhe propiciamos meios para o pensar autêntico, porque, recebendo as fórmulas que lhe damos, simplesmente as guarda. Não as incorpora porque a incorporação é o resultado de busca de algo que exige, de quem o tenta, esforço de recriação e de procura. Exige reinvenção. (FREIRE, 2015, p. 98).
}

Para efetivarmos a presente proposta/alternativa à luz da crítica freireana, apresentamos AmarElo segundo uma perspectiva fenomenológica que desconfia e lança questionamentos ao 
que aparece muitas vezes como o "normal" educativo. No contexto escolar, as relações que poderiam figurar como espaços de reflexão criadora têm nos afazeres burocráticos e curriculares situações que muitas vezes desencorajam docentes e discentes a avançarem para além do que está estabelecido institucionalmente. Diante disso, um dos caminhos para o debate parece-nos evidente na música de Emicida, um artista brasileiro preocupado, conforme veremos neste estudo, em transcender a realização fonográfica.

Nossa abordagem sobre temas como língua, trabalho, racismo e questões de gênero, instigada por AmarElo, traz, em um primeiro momento, fragmentos das faixas e alguns entre os vários posicionamentos críticos publicados sobre o álbum. Posteriormente, realizamos o intento de leitura seguido das considerações finais. Resulta deste estudo, especialmente, um chamado às reconsiderações pedagógicas que, como parte importante de nossa constituição social, devem surgir constantes no pensar decorrente de investigações e práticas. Essas são questões inadiáveis que, no âmbito da arte, estão postas de modo contundente, a exemplo do que passamos a expor na sequência.

\section{AMARELO, O ELO ENTRE A ARTE E A VIDA}

Em 2019, Emicida traz a público seu terceiro álbum de estúdio, composto por 11 faixas, todas elas como resultado de uma busca por "[...] evidenciar de onde emana o poder verdadeiro; incentivar que as pessoas observem ao redor e se enxerguem maiores do que os seus problemas; e gritar pelo direito de poder viver, resistir e amar da sua forma" (BME, 2019, s. n.). O título inspira-se no poema de

\footnotetext{
Paulo Leminski (amar é um elo/ entre o azul/ e o amarelo), [e] o artista busca reunir heranças, referências e particularidades encontradas na magnitude da música brasileira e aplicar a elas olhares e aprendizados que acumulou desde o lançamento da sua primeira (e clássica) mixtape 'Pra Quem Já Mordeu um Cachorro por Comida Até Que Eu Cheguei Longe...' (2009).” (BME, 2019, s. n.).
}

AmarElo revela-se desde o título como um mosaico de referências presentes direta ou indiretamente nas letras da faixas, nas participações especiais, nos ritmos, nas cadências, nos sons. $\mathrm{O}$ amor e o elo, como sugeriu certa feita o poeta paranaense, revigoram-se em forma de manifesto diante do mundo em transformação e, especialmente, como resultado do momento do artista em sua caminhada de leituras, compreensões e expressão.

A capa não foge a essa constante e, de acordo com Ricardo Alexandre (2019, s. n.), foi produzida por "[...] Claudia Andujar (uma foto de 1974 que Emicida achou parecida com 'Stakes is High', do De La Soul)". Conforme podemos notar logo abaixo, tanto a imagem escolhida pelo grupo americano de hip-hop quanto a apresentada pelo músico brasileiro 
revelam, especialmente, os olhares de crianças que, além de expressarem curiosidade e destemor diante da câmera, expõem-se como pessoas no mundo, em suas realidades possíveis, para cumprirem destinos de sonhos, a partir dos caminhos que a elas serão oportunizados:

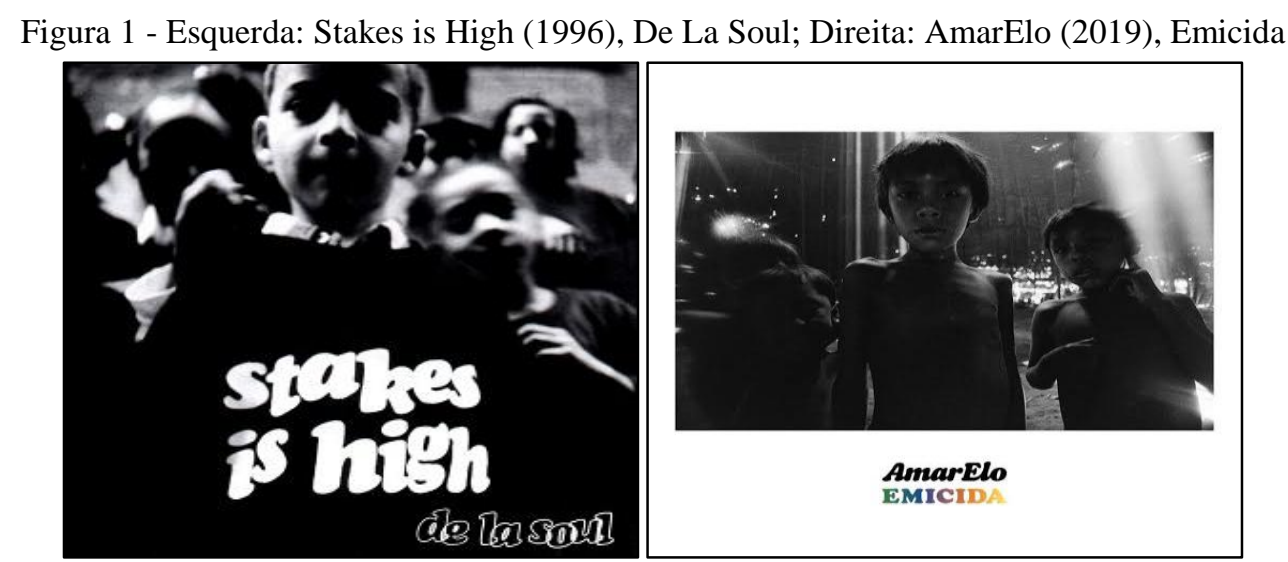

Fontes: https://en.wikipedia.org/wiki/Stakes_Is_High e http://genius.com/albums/Emicida/Amarelo.

Diante dessas imagens, compreendemos melhor as palavras de Ricardo Alexandre (2019, s. n.) quando afirma que AmarElo "[...] é um disco que propõe desarmar a bomba de intolerância, egoísmo, extremismos e autoindulgência que transformaram o Brasil num barril de pólvora. A questão é menos o sistema e mais o ser humano. [...]”. Conforme Emicida, ainda mais específico, "[...] o que eu faço com o meu trabalho, com minha capacidade de construir coisas, é tentar deixar o mundo no nível das crianças." (apud ALEXANDRE, 2019, s. n.). O álbum, assim, é convite a todos nós e, em grande medida, àqueles que trabalham com educação e podem, ao atentarem para músicas como as que apresentamos a seguir, redescobrirem-se, reforçarem ou reavaliarem sua prática docente.

A primeira faixa, "Principia", tem a participação do pastor Henrique Vieira, Fabiana Cozza e das Pastoras do Rosário. Mescla cantos de fundo, batida forte, letras com "momentos falados/ritmados" ao estilo rap e melodia musicada a exemplo do refrão. Não é por acaso que Pedro Alexandre Sanches (2019, s. n.) chama a atenção para o seguinte: "O rap de Emicida tem se encaminhado lentamente na direção da canção, e AmarElo é, até aqui, o ponto culminante dessa trajetória." Em várias críticas ao álbum aparece a palavra "canção" e, se a tomarmos a partir da noção de composição musical de caráter popular, como gênero híbrido e mutante desenvolvido ao longo do século XX, parece-nos cabível sua relação ao álbum ora em análise.

Em "Principia" o artista oferece desde versos como "Cale o cansaço/ Refaça o laço/ Ofereça um abraço quente/ A música é só uma semente/ Um sorriso ainda é a única língua que todos entendem", até momentos que se aproximam a palavras de ordem: 
Num tempo onde a única que ainda corre livre aqui/ São nossas lágrimas/ Eu voltei pra matar tipo infarto/ Depois fazer renascer, estilo um parto/ Eu me refaço, farto, descarto/ De pé no chão, homem comum/ Se a bênção vem a mim, reparto/ Invado cela, sala, quarto/ Rodei o globo, hoje tô certo de que/ Todo mundo é um/ Tudo, tudo, tudo, tudo/ Que nóiz tem é nóiz [...] (EMICIDA, 2019).

Refazer o laço entre as pessoas diante da vida e oferecer um abraço a partir da semente da música são tônicas recorrentes, um projeto, mas sem a ingenuidade de que o mundo social seja igual para todos. A liberdade das lágrimas não é a mesma do direito ao lazer e à educação, ao emprego dignamente remunerado, à expressão das crenças e das artes, ao ir e vir sem ser barrado pela polícia por não estar de acordo com as características ideias de determinados lugares. Por isso, o artista se refaz, viaja pelo mundo e volta para dizer que "todos somos um" e o que temos somos uns aos outros. "Tudo é África”, está na letra, e como fala o pastor, “[...] enquanto houver amor/ Eu mudarei o curso da vida/ [...] Até ver o ubuntu da emancipação/ Porque eu descobri o segredo que me faz humano/ Já não está mais perdido o elo/ O amor é o segredo de tudo/ E eu pinto tudo em amarelo." Com esta faixa cujo título tem inspiração no estudo homônimo de Isaac Newton (MARANGON, 2020), portanto, convida-se o ouvinte/leitor para as subsequentes.

Em "Ordem natural das coisas", com a participação de Mc Tha, o cotidiano do trabalho vem à tona com: “A merendeira desce/ O ônibus sai/ Dona Maria já se foi/ Só depois é que o sol nasce/ De madruga é que as aranhas tecem/ No breu/ E amantes ofegantes/ Vão pro mundo de morfeu/ E o sol só vem depois/ O sol só vem depois [...]” (EMICIDA, 2019). O produtor da música, Damien Seth, optou por destacar o canto de passarinhos, pois, conforme entrevista de Emicida, foi enviado um áudio guia, “[...] cantando só o refrão, pra ele sacar mais ou menos qual era a ideia. Lá em casa, eu moro num lugar que é muito arborizado, então tem muitos pássaros, todas as horas do dia tem pássaro cantando. A noite dá uma diminuída e passa só uns morcegos.” (FERRAZ; ROCHA, 2019, s. n.).

O contexto da música pronta e o contexto da produção, assim, aproximam-se como duas expressões da vida comum, das pessoas em suas habitações, aquelas que saem muito cedo para o trabalho, aquelas que amam e sonham na madrugada, e dos artistas que direcionam a sensibilidade observadora do mundo para a obra. Em um movimento infinito, haveria uma ordem natural em que estamos inseridos, mas, entre o que é e o que aparece-nos como naturalidade, existem nuances e diferenças sobre as quais devemos estar atentos, conforme AmarElo irá apontar em vários momentos.

Em "Pequenas Alegrias da Vida Adulta", com a participação de Thiago Ventura, versos como "Eu vou.../ Pro front como um guerreiro/ Nem que seja pra enfrentar o planeta inteiro/ 
Correr a maratona, chegar primeiro/ E gritar: - é por você amor [...]” (EMICIDA, 2019) completam-se, em alguma medida, com "Cananéia, Iguape e Ilha Comprida" em que o artista inicia com uma gravação caseira falando à sua filha mais nova: “[...] Pra trabalhar nesse emprego de rapper, você tem que ser mau!/ Tendeu? Sem risadinha, ok?/ Será que o Brown passa por isso? Ou o Djonga? Ou o Rael?/ Sei lá, meu. Aqui os cara é mau!’”(EMICIDA, 2019). A música segue, anunciando: "Do fundo do meu coração/ Do mais profundo canto em meu interior/ Pro mundo em decomposição/ Escrevo como quem manda cartas de amor [...]" (EMICIDA, 2019).

Essa faixa, e agregaríamos a primeira também, está entre as canções “[...] que se revelam ao público como pequenos refúgios sentimentais, [...] porém, sempre de forma consciente, sóbria, como se Emicida jamais fechasse os olhos e tapasse os ouvidos para o ambiente que o cerca." (FACCHI, 2019, s. n.). Estar atento ao ambiente e às questões importantes, históricas e sociais, mostram-se, em um primeiro momento, na quantidade de parcerias, de diversos seguimentos artísticos, que vêm consolidando-se desde os álbuns anteriores do artista. Na faixa "Quem Tem Um Amigo (Tem Tudo)", com a participação da Tokyo Ska Paradise Orchestra e de Zeca Pagodinho, isso é notório nos versos: "Se a bala come, mano, ele se põe de escudo/ Pronto pro que vier, mesmo, a qualquer segundo/ É um ombro pra chorar depois do fim do mundo [...] Logo perguntei para Oxalá e pra Nossa Senhora:/ - Em que altura você mora agora? Um dia lhe visitarei [...]" (EMICIDA, 2019). Nessa faixa, há referência e reverência à amizade de Gil e Caetano, além de homenagem ao falecido Wilson das Neves, “[...] meu eterno parceiro, o orixá que tivemos a honra de conhecer em vida" (EMICIDA, 2019) que, no álbum O glorioso retorno de quem nunca esteve aqui (2013), cantou na faixa "Trepadeira".

A partir de "Paisagem", faixa com características do rock, guitarras, etc., o que antes já aparecia em versos críticos, passa a ganhar mais objetividade em momentos como: “[...] a rede social dá o que nóiz quer/ Enquanto rouba o que nóiz precisa/ Porque nada é sólido, nada [...] Quem diria, a pobreza de espírito aqui/ Fez a de grana se tornar um detalhe/ Dizem os jornais:/ - Calma rapaz, espere e verás, tudo está em paz [...]" (EMICIDA, 2019). Para Kerolin Andrade (2019, s. n.) trata-se da "[...] faixa mais sincera do álbum, nela Emicida reflete seu interior falando abertamente sobre seus medos e anseios, dúvidas e da única certeza que pode ter é a escolha de apreciar as flores [...]". Para somar à diversidade sonora, em "9nha", com a participação de Drik Barbosa, a “[...] love song do disco mistura MPB com jazz na faixa mais cantada do álbum.” (ANDRADE, 2019, s. n.). O artista canta: “[...] Num mundo de dar medo, ela me dava coragem, morô?/ E a sintonia monstra, neguim [...]” (EMICIDA, 2019). 
"Eminência Parda", com a participação de Dona Onete, Jé Santiago e Papillon, trata-se de "[...] uma exaltação ao povo preto, utilizando de pequenas conquistas pessoais do rapper como um exercício de ocupação e estímulo para a formação dos versos.” (FACCHI, 2019, s. n.). Os trechos “[...] Me sinto tipo a invenção do zero/ Num sou convencido, sou convincente/ Vê na rua o que as rima fizeram [...] Pastoreio a negra ovelha que vagou dispersa/ Polinização pauta conversa/ Até que nos chamem de colonização reversa [...]" (EMICIDA, 2019) surgem como um convite coerente para a faixa seguinte, "AmarElo" que, além de dar nome ao álbum, apresenta um sample de "Sujeito de sorte", de Belchior, e traz a participação de Majur e Pabllo Vittar:

[...] É um mundo cão pra nóiz, perder não é opção, certo?/ De onde o vento faz a curva, brota o papo reto/ Num deixo quieto, num tem como deixar quieto/ A meta é deixar sem chão, quem riu de nóiz sem teto/ Tenho sangrado demais, tenho chorado pra cachorro/ Ano passado eu morri mas esse ano eu não morro [...] Por fim, permita que eu fale, não as minhas cicatrizes/ Achar que essas mazelas me definem, é o pior dos crimes/ É dar o troféu pro nosso algoz e fazer nóiz sumir [...] (EMICIDA, 2019).

"AmarElo" busca "[...] deixar claro que a proeza de ninguém pode ser resumida ao mero ato de sobreviver. Emicida se permite falar com as cores vivas de quem defende uma vida plena de sentidos e sonhos para o povo das filas, vilas e favelas." (FERREIRA, 2019, s. n.). Essa plenitude ecoa na faixa seguinte, "Libre", com a participação das “[...] irmãs franco-cubanas Ibey e mistura uma batida inspirada no funk com ritmos latinos para levar uma mensagem de liberdade interior e exterior" (ANDRADE, 2019, s. n.). Ao cantar “[...] Libre, libre, libre/ Noiz/ Libre/ Aqui somos libre [...] To freedom forever like/ Mandela Mandela Mandela/ There is no discussion/ Favela, favela, favela [...]" (EMICIDA, 2019), línguas, referência e local de moradia encontram-se como grito à pluralidade a que devemos estar atentos.

Nessa direção, a última faixa, "Ismália", com a participação de Larissa Luz e de Fernanda Montenegro, é o fechamento instigante de um projeto cuja realização tem nas palavras de Emicida, em entrevista, uma alusão à gravação da música que tem muito a ver com o sentimento geral do álbum:

[...] lá no estúdio, converso com ela [Fernanda Montenegro] contextualizando "Ismalia" no disco, dizendo pra ela que acho que hoje "Ismalia" é mais urgente do que no século XIX porque [...] fala muito sobre a experiência de vida, principalmente das pessoas de pele escura. E ela já tinha gravado. Depois dessa conversa, ela fala: "Eu acho que a gente tem que gravar de novo". Daí ela entra no estúdio, com uma humildade gigante. "A interpretação pede um outro estado de espirito" e vai lá pra fazer. Seu camarada Emicida fica assim ó [cara de choro], olhando a Nossa Senhora do "O Auto da Compadecida" dentro do estúdio. Parceiro, quem vai bater de frente? A mãe de Deus tá com nóis! [...] (FERRAZ; ROCHA, 2019, s. n.). 
Em "Ismália”, conforme Andrade (2019, s. n.), "[...] a mensagem confronta as estruturas sociais e faz referências a casos de violência que repercutiram pelo país, o som é um grito." No trecho “[...] Olhei no espelho/ Ícaro me encarou/ Cuidado, não voa tão perto do sol/ Eles não aguentam te ver livre [...] Ismália, Ismália/ Quis tocar o céu, mas terminou no chão [...] 80 tiros te lembram que existe pele alva e pele alvo [...] Quem disparou usava farda (mais uma vez) [...]" (EMICIDA, 2019), mitologia, literatura e fato recente da história brasileira se confundem. A leitura do poema de Alphonsus de Guimaraens, feita por uma das mais importantes atrizes do Brasil, completa as significações de um álbum cujos aspectos, impossível abarcá-los em sua totalidade, ajudam-nos a pensar em educação e atividade docente na sociedade contemporânea, sobre as quais tecemos considerações a seguir.

\section{Por uma PEDAgogia do ENCONTRO}

Entre os elementos envolvidos na composição de AmarElo, a variedade de registros linguísticos chama a atenção. O "som das ruas" e a linguagem das referências poéticas e históricas encontram-se sem preconceitos, a serviço da arte, livre das imposições sociais que estratificam o "quando", "como" e "onde" devemos falar. O contexto do álbum convida e dá passagem para expressões que vão desde "tudo que nóiz tem é nóiz", passando por "logo perguntei para Oxalá e pra Nossa Senhora", "aqui somos libre [...] to freedom forever", "Ícaro me encarou", até a leitura de "Ismália" realizada por Fernanda Montenegro. Outra constante, são as referências à cultura universal que também aparecem nos álbuns anteriores (EMICIDA, 2013; 2016) nos quais o espaço dado à palavra poética falada também são marcantes, por exemplo, nas vozes de Elisa Lucinda e Dona Jacira.

Junto a isso, relatos despreocupados como o momento com a filha em "Cananéia, Iguape e Ilha Comprida" ou o telefonema do amigo Thiago Ventura em "Pequenas Alegrias da Vida Adulta" (EMICIDA, 2019) contando a história do roubo do rádio de um carro, ajudam-nos a pensar a noção de que a “[...] palavra, como fenômeno ideológico por excelência, está em evolução constante, reflete fielmente todas as mudanças e alterações sociais. O destino da palavra é o da sociedade que fala.” (BAKHTIN, 2006, p. 199). Nessa direção, o que compõe AmarElo é a palavra viva por excelência, sem problemas de estratificação. Ali todos podem falar, "mandar sua mensagem", sem preocuparem-se com a correção do registro linguístico.

Somam-se à liberdade de línguas e linguagens a quantidade multifacetada de referências e participações musicais. Emicida é um sujeito agregador. Seu talento é elogiado e correspondido por nomes representativos de distintos ramos da música, das letras, artes cênicas, 
religião, enfim, da sociedade que é tão múltipla quanto seu projeto artístico. Nessa verdadeira comunidade, o diálogo indireto e direto com vertentes pessoais e sociais de conhecimento avulta na abordagem de temas que nos rodeiam há muito tempo. Eles, porém, agora parecem inadiáveis e o artista não está disposto a deixá-los passar sem que sua voz seja lançada.

A urgência coletiva de se pensar a vida e o encontro entre as pessoas ecoa, por exemplo, no projeto de Podcast “AmarElo Prisma” que já lançou quatro episódios destinados a cuidar do corpo e da mente. No primeiro deles, denominado "Movimento 1", temos a ideia do todo ao depararmo-nos com o depoimento/ensinamento de "[...] pessoas que trazem repertórios diferentes, seja pelo meio de atuação, pela vivência ou, até mesmo, por sua localização geográfica dentro do Brasil. Projetam luz no prisma [...].” (2020, s. n.). O percurso do álbum iniciado pela música segue, assim, buscando parcerias e, "atravessando" luminosidades como no uso newtoniano do prisma - mais uma referência ao cientista que também inspirou o título da faixa "Principia" -, oferece cuidados essenciais à saúde, à esperança da união e da luta. A valorização do lugar, da terra, tem o amor como eixo, o elo perdido entre as pessoas que queremos ao nosso lado, em uma reafirmação da sociabilidade cujas raízes também estão no rap, na crítica e na busca da comunhão.

O cotidiano do trabalhador também ganha espaço no álbum em situações que nos fazem pensar sobre as pessoas que, no mínimo, trabalham oito horas por dia, sete dias por semana e, muitas vezes, não têm direito às horas restantes para o descanso, lazer, estudos, etc. Mesmo assim, há mulheres e homens que subvertem o determinismo social e buscam enfrentar uma jornada extra, especialmente na sala de aula, lugar onde uma boa perspectiva de futuro para os pobres se apresenta. O que move e alimenta essa coragem de entregar horas de vida para estudar talvez seja, conforme ouvimos em um trecho da faixa "AmarElo", “[...] pra que amanhã não seja só um ontem, com um novo nome" (EMICIDA, 2019).

A expectativa de uma realidade diferente leva à vontade de aprender, vislumbrar sonhos, metas, acreditar em uma vida melhor não só para si, mas para os "seus". Essa expectativa tem a ver com o viés emancipatório da educação, ou seja, o trabalhador, ao vencer o cansaço e todas as barreiras colocadas por uma sociedade mal-intencionada, pode libertar-se de uma realidade (im)posta e partir para a construção de uma nova realidade, antes possível apenas nos sonhos frustrados. Há nessa busca o início de "[...] um esforço permanente através do qual os homens vão percebendo, criticamente, como estão sendo no mundo com que e em que se acham." (FREIRE, 2013, p. 78). Neste movimento teorizado pelo educador brasileiro e retomado por 
Emicida, temos a chance de problematizar nosso "estar no mundo" e, consequentemente, perceber criticamente as condições histórico-sociais em que estamos inseridos.

A denúncia sobre o racismo e suas facetas é, por outro lado, um dos temas que mais predominam nas composições de Emicida - considerado um ativista frente à representatividade nas e pelas comunidades negras do Brasil. O "experimento social" que ele tem elaborado nos seus discos, aqui evidenciado em nossa leitura de AmarElo, é apresentado como discursos de resistência em contextos políticos, sociais, culturais, etc. Contribui para pensarmos um modelo novo, com novas "medidas civilizatórias" frente às desigualdades existentes em um mundo onde os “[...] comportamentos individuais e processos institucionais são derivados de uma sociedade cujo racismo é regra e não exceção". (ALMEIDA, 2019, p. 50). A resistência experimentada nas canções de Emicida simboliza a necessidade de reconhecer-se e posicionarse face a qualquer forma de dominação.

O álbum transmite mensagens fundamentais, atuais, sobre a diversidade, o enfrentamento e o esforço de atribuir sentidos restituidores às teorias racistas que organizaram a sociedade brasileira, acometidas historicamente aos excluídos, marginalizados ou opacizados - negros, negras, índios, índias, LGBTQIA+, pobres - pelo sistema. É, portanto, um chamado a todos para uma possibilidade de escuta recíproca. Emicida ainda completa: "reescrever a história, esse é o barato que eu corro atrás" (DEHÓ, 2018, s. n.). Essas palavras levam-nos a entender que devemos pluralizar os debates, interseccionar os discursos e não legitimar a reprodução de uma história "única" que nosso país está atreito.

Se hoje vemos a escola voltada à reprodução de uma sociedade envolta por influências liberais, por métodos de avaliação que seguem a base da meritocracia, recriando níveis dicotômicos entre alunos bons e ruins, usando parâmetros de notas obtidas sem considerar o ponto de partida de cada aluno, devemos questionar esse processo. As práticas docentes, conforme as concebemos a partir de AmarElo, poderiam estar voltadas também aos interesses individuais e coletivos, de modo a tornarem-se um eixo de influência social. Provocar a curiosidade dos estudantes e potencializar o aprendizado, unir e problematizar os conhecimentos. Somar a cultura universal à história oral das minorias que, muitas vezes, por não dominarem a língua escrita ou as práticas de verbalização segundo os padrões normativos - ou por não estarem adequadamente vinculados à "moralidade" ideal da comunidade religiosa e economicamente dominante - não estão contempladas nos currículos.

Pensar a educação deve ser, necessariamente, refletir sobre a crise institucional que passa despercebida ou pelo menos é pouco discutida de maneira democrática. O degastado "a 
educação é para todos" intercorre somente para determinado grupo (o privilegiado). Mesmo passados anos desde a constituição elementar da escola (pública), a distância entre o discurso de construção e as ações efetivas parecem não se estreitar. Ainda é urgente a crítica de Paulo Freire para quem o ditado e a discursivização não podem ser o "normal", no lugar da troca, do debate e da discussão de ideias e temas. Trabalhar "com" e não "sobre" deverá ser o caminho necessário em direção ao pensar autêntico, à criatividade, à reinvenção. De maneira ampla, discutir a equiparação histórica é trazer à baila questões raciais, sociais e de linguagem, no intento de repensar as políticas públicas, tendo em vista a pluralidade dos sujeitos viventes.

A prática docente, assim como Emicida (2019) canta em "Principia", "é só uma semente". Seja na arte ou na postura dos enunciados de professores e estudantes, devemos estar atentos à nossa condição de sujeitos que pedem e suscitam apelo de um lugar de fala, mas também de um espaço de/para escuta. Nessa interlocução, evidenciaremos e nos posicionaremos em prol das vozes que clamam por uma fissura e, assim, não teríamos palavras melhores que a do próprio Emicida (2020, s. n.) para fecharmos esta parte de nossa reflexão: "A gente está colocando tijolinho por tijolinho para construir essa ponte que vai levar a gente para um lugar melhor."

\section{CONSIDERAÇÕES FINAIS}

Ao construímos este artigo, a partir do diálogo entre três investigadores interessados no debate sobre a educação na sociedade contemporânea, tivemos o intuito de pensar o álbum AmarElo como um exemplo de postura cabível também nas atuações pedagógicas. Não foi nosso objetivo indicar procedimentos didáticos nem orientar abordagens em disciplinas específicas. Sugerimos como marco de reflexão o Ensino Médio, mas não de modo fechado, pois nesse contexto aos estudantes pode parecer instigante participarem da discussão de temas tão importantes quanto os desenvolvidos por Emicida.

A ideia freiriana de educação como lugar de intervenção no mundo, seja para reprodução ou desmascaramento de ideologias, leva-nos especialmente à segunda opção quando passamos a encarar a escola como campo de ação docente para questões centrais, históricas e cotidianas. Nesse aspecto, temas como o trabalho e o racismo, entre outros, reelaborados em termos de arte nas letras aqui apresentadas, têm na musicalidade do artista direcionadores de atuação aos quais nós, educadores, deveríamos ficar atentos.

A educação escolar e pessoal passa pelo mosaico de referências de nossas leituras, pelos laços que constituímos entre colegas, alunos e as interações sociais ao longo da vida. São 
encontros que estabelecemos e deveriam ocorrer, também por meio deles, os nossos aprendizados, para além das disciplinas, notas, aprovações e reprovações. Emicida é um artista que transita por essas vertentes e sua obra, como pudemos notar em AmarElo, é um convite à reflexão. Sejamos atentos, portanto, à relevância de constituirmos parcerias, considerarmos a pluralidade de assuntos, pontos de vista, expressões e, especialmente, não ficarmos passíveis e acríticos em relação ao que é proposto/imposto como modo correto de compreensão.

\section{REFERÊNCIAS}

ALEXANDRE, Ricardo. As transformações de Emicida em seu álbum "Amarelo". Reverb, 2019. Disponível em https://reverb.com.br/artigo/as-transformacoes-de-emicida-em-seualbum-amarelo Acesso em: 01 mai. 2020.

ALMEIDA, Silvio Luiz de. Racismo estrutural. São Paulo: Sueli Carneiro; Pólen, 2019.

ANDRADE, Karolyn. Em “AmarElo”, Emicida está em paz. KondZilla, 2019. Disponível em https://kondzilla.com/m/em-amarelo-emicida-esta-em-paz/\#materia Acesso em: 25 jun. 2020.

BAKHTIN, Mikhail. Marxismo e filosofia da linguagem. São Paulo: Hucitec, 2006.

BME. Emicida lança novo projeto de estúdio: AmarElo. Brasil Music Exchange, 2019. Disponível em http://brmusicexchange.com/emicida-lanca-novo-projeto-de-estudio-amarelo/. Acesso em: 01 mai. 2020.

DEHÒ, Maurício. A música é uma arma... e 2018 é um ano de guerra: como Emicida quer rimar os próximos dez anos de luta. UOL Entretenimento, 2018. Disponível em https://www.uol/entretenimento/especiais/emicida.htm\#reforma-agraria-das-artes Acesso em: 29 jun. 2020.

EMICIDA. Emicida - O Glorioso Retorno de Quem Nunca Esteve Aqui (álbum completo). YouTube, 2013. Disponível em https://www.youtube.com/watch?v=ShnL2LeCj4\&list=OLAK5uy mkvbBfweeY_Ok87-5RcDwFpMbWuYqkrBo\&index $=8$ Acesso em: 19 jun. 2020.

EMICIDA. Emicida - Sobre Crianças, Quadris, Pesadelos e Lições de Casa.. (álbum completo). YouTube, 2016. Disponível em https://www.youtube.com/watch?v=D_j32_Ryc0\&list=OLAK5uy_lgU8JGuLHZyONP1lpCIJI8zUFWFX-YdC8 Acesso em: 19 jun. 2020.

EMICIDA. Emicida - AmarElo (álbum completo). YouTube, 2019. Disponível em https://www.youtube.com/playlist?list=PL_N6VL1gm0aLlrOHQ6yl2IRXdSfuxMt-s Acesso em: 19 jun. 2020.

EMICIDA. Emicida faz reflexão sobre a realidade do Brasil. Gshow, 2020. Disponível em https://gshow.globo.com/programas/domingao-do-faustao/noticia/emicida-faz-reflexao-sobrea-realidade-do-brasil-letal-sao-os-abismos-sociais-que-a-nossa-sociedade-produziu.ghtml Acesso em: 30 jul. 2020. 
FACCHI, Cleber. Crítica | Emicida: “AmarElo". Miojoindie, 2019. Disponível em http://miojoindie.com.br/critica-emicida-amarelo/ Acesso em: 26 jun. 2020.

FERRAZ, Gabriela; ROCHA, Guilherme Lucio da. 7 segredos de "AmarElo" que o Emicida quer muito te contar. BuzzFeed, 2019. Disponível em https://www.buzzfeed.com/br/gabrielaferraz/7-segredos-de-amarelo-que-o-emicida-quermuito-te-contar Acesso em: 25 jun. 2020.

FERREIRA, Mauro. Emicida se permite falar, no discurso social de 'AmarElo', de vida plena de sentidos e sonhos. G1, 2019. Disponível em https://g1.globo.com/pop-

arte/musica/blog/mauro-ferreira/post/2019/06/26/emicida-se-permite-falar-no-discurso-socialde-amarelo-de-vida-plena-de-sentidos-e-sonhos.ghtml Acesso em: 26 jun. 2020.

FREIRE, Paulo. Pedagogia da autonomia: saberes necessários à prática educativa. São Paulo: Paz e Terra, 2011.

FREIRE, Paulo. Pedagogia do oprimido. [Recurso eletrônico]. Rio de Janeiro: Paz e Terra, 2013.

FREIRE, Paulo. Educação como prática da liberdade. [Recurso eletrônico]. Rio de Janeiro: Paz e Terra, 2015.

LABORATÓRIO FANTASMA. AmarElo Prisma. Google Podcasts, 2020. Disponível em https://podcasts.google.com/feed/aHR0cHM6Ly93d3cuc3ByZWFrZXIuY29tL3Nob3cvNDQ wNzYxOC91cGlzb2Rlcy9mZWVk?sa=X\&ved=0CAIQ4aUDahcKEwjg_5a_n4LrAhUAAAA AHQAAAAAQBA Acesso em: 04 ago. 2020.

MARANGON, Vini. Professores de Física comentam Principia do Emicida. YouTube, 2020. Disponível em https://www.youtube.com/watch?v=RCvUhM0ArEA Acesso em: 03 ago. 2020.

SANCHES, Pedro Alexandre. Emicida visita a canção em "AmarElo”. Farofafá, 2019. Disponível em https://farofafa.cartacapital.com.br/2019/11/07/emicida-visita-a-cancao-emamarelo/ Acesso em: 19 jun. 2019.

Recebido em: 30 de junho de 2020.

Aprovado em: 13 de agosto de 2020. 